\title{
Structural and Morphometric Comparison of Lower Incisors in PACAP-Deficient and Wild-Type Mice
}

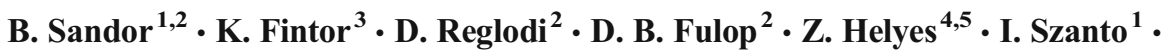

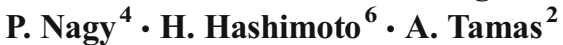

Received: 30 March 2016 / Accepted: 27 April 2016/Published online: 6 May 2016

(C) Springer Science+Business Media New York 2016

\begin{abstract}
Pituitary adenylate cyclase activating polypeptide (PACAP) is a neuropeptide with widespread distribution. PACAP plays an important role in the development of the nervous system, it has a trophic and protective effect, and it is also implicated in the regulation of various physiological functions. Teeth are originated from the mesenchyme of the neural crest and the ectoderm of the first branchial arch, suggesting similarities with the development of the nervous system. Earlier PACAP-immunoreactive fibers have been found in the odontoblastic and subodontoblastic layers of the dental pulp. Our previous examinations have shown that PACAP deficiency causes alterations in the morphology and structure of the developing molars of 7-day-old mice. In our present study, morphometric and structural comparison was performed on the incisors of 1-year-old wild-type and PACAPdeficient mice. Hard tissue density measurements and morphometric comparison were carried out on the mandibles and the lower incisors with micro-CT. For structural examination, Raman microscopy was applied on frontal thin sections
\end{abstract}

A. Tamas

andreatamassz@gmail.com

1 Department of Dentistry, Oral and Maxillofacial Surgery, Pecs, Hungary

2 Department of Anatomy, MTA-PTE “Lendulet” PACAP Research Team, Szigeti 12, Pecs 7624, Hungary

3 Department of Mineralogy, Geochemistry and Petrology, Faculty of Science and Informatics, University of Szeged, Szeged, Hungary

4 Department of Pharmacology and Pharmacotherapy, Medical School, Szentagothai Research Center, University of Pecs, Pecs, Hungary

5 MTA-NAP B Chronic Pain Research Group, Pecs, Hungary

6 School of Pharmaceutical Sciences, Osaka University, Osaka, Japan of the mandible. With micro-CT morphometrical measurements, the size of the incisors and the relative volume of the pulp to dentin were significantly smaller in the PACAPdeficient group compared to the wild-type animals. The density of calcium hydroxyapatite in the dentin was reduced in the PACAP-deficient mice. No structural differences could be observed in the enamel with Raman microscopy. Significant differences were found in the dentin of PACAP-deficient mice with Raman microscopy, where increased carbonate/ phosphate ratio indicates higher intracrystalline disordering. The evaluation of amide III bands in the dentin revealed higher structural diversity in wild-type mice. Based upon our present and previous results, it is obvious that PACAP plays an important role in tooth development with the regulation of morphogenesis, dentin, and enamel mineralization. Further studies are required to clarify the molecular background of the effects of PACAP on tooth development.

Keywords PACAP · Raman · Tooth · Development · Micro-CT

\section{Introduction}

Pituitary adenylate cyclase activating polypeptide (PACAP) is a member of the vasoactive intestinal polypeptide (VIP)/secretin/growth hormone-releasing hormone/glucagon superfamily. It is a multifunctional neuropeptide, with widespread distribution. PACAP-27, and PACAP-38 are the two known bioactive forms. There are three recognized receptors of PACAP: the PACAP-specific PAC1 and VPAC1 and VPAC2 receptors, which bind PACAP and VIP with equal affinity (Vaudry et al. 2009). This, and the different ligandbinding properties of the PAC1 receptor splice variants explain the pleiotropic activities of PACAP (Blechman and 
Levkowitz, 2013). PACAP plays a role in the regulation of basic physiologic functions and has trophic and protective effects in the central and peripheral nervous system (Arimura et al. 1994; Watanabe et al. 2007; Vaudry et al. 2009; Reglodi et al. 2011; Shen et al. 2013). Thanks to the effects of PACAP in the development of the nervous system and various organs, PACAP has been mentioned as one of the trophic factors. Among others, it plays important roles in bone and cartilage development and growth. This has been proven in vitro in osteoblast and chondroblast cultures and in vivo, using PACAP-deficient mice, suggesting the endogenous functions of the peptide (Kiss et al. 2010; Juhasz et al. 2014, 2015a). PACAP deficiency leads to various other developmental alterations (Hashimoto et al. 2001, 2009; Reglodi et al. 2012; Tajiri et al. 2012; Juhasz et al. 2015a).

Teeth develop from the oral ectodermal- and cranial neural crest-derived mesenchymal cells (Thesleff and Nieminen, 1996). More than 300 factors are involved in tooth development (Thesleff, 2006). Many studies have shown interactions between PACAP and factors of tooth development (Otto et al. 2000; Nicot et al. 2002; Lelievre et al. 2006; Hirose et al. 2011; Niewiadomski et al. 2013; Juhasz et al. 2015b). Earlier PACAP-immunoreactive fibers were detected in the tooth pulp (Ichikawa and Sugimoto, 2003), and it has been shown that it plays a role in the regeneration of the periodontium after luxation of the teeth (Nonaka et al. 2013). Our previous study on 7-day-old PACAP-deficient and wild-type mice suggested that PACAP may also play a role in the development of the molar teeth. With morphometric analysis, we found that the dentin layer in PACAP-deficient mice was significantly thinner. Structural comparison with Raman microscopy showed differences in the protein structure of the enamel and the hydroxyapatite structure of the dentin. Higher heterogeneity could be observed in the secondary structure of proteins of the enamel in wild-type mice. The examination of the dentin showed higher carbonate substitution (B-type) in PACAP-deficient mice, resulting in the disturbance of lattice structure with higher disordering and less crystalline bioapatite structure (Sandor et al. 2014).

In our previous study we have shown that there are differences between the developing molars in the pre-eruptive stage of wild-type and PACAP-deficient mice. Nonetheless, the lack of PACAP might have different effects on the continuous growth of the incisors in adult mice, as it has been described earlier that depletion of genetic factors involved in tooth development may affect molar and incisor development and mineralization in a different manner (Goldberg et al. 2014; Sandor et al. 2014). In our present study, we carried out morphometric measurements with micro-CT system in 1-year-old wild-type and PACAP-deficient mice. Structural comparison was performed between the lower incisors, which show continuous lifetime growth. We analyzed the dentin, the enamel and the mandibular bones of the two groups with tissue mineral density (TMD) measurements with CT-analyzer software. We also used Raman microscopy for further structural analyses of the hydroxyapatite and protein structures of the dentin and the enamel layer of the incisors.

\section{Materials and Methods}

\section{Animals}

PACAP-deficient male mice were generated and maintained on CD1 background as described previously (Hashimoto et al. 2001, 2009). The genotyping of the mice was performed with polymerase chain reaction. For our study, we used wild-type (PACAP $+/+; n=5$ ) and homozygous PACAP-deficient (PACAP $-/-; n=6$ ) mice. The mice were kept under light/ dark cycles of $12 / 12 \mathrm{~h}$ with free access to food and water. The study was carried out in accordance with ethical guidelines of the University of Pecs, Hungary (BA02/2000-15,024/2011).

\section{Preparation of Samples for Morphometric and Density Measurements with Micro-CT}

One-year-old animals were sacrificed with an overdose of pentobarbital (Nembutal, Sanofi-Phylaxia, Hungary). The mandibles (both left and right side) of the animals were dissected. After the removal of the soft tissues the samples were immediately stored in physiological saline to prevent dehydration. Before CT scanning, the mandibles were aligned with dental wax. The samples were scanned by using a highresolution in vivo micro-CT system (Skyscan 1176, Bruker MicroCT, Kontich, Belgium) with a voxel size of $9 \mu \mathrm{m}$. For tissue mineral density (TMD) measurements, phantom rods were used for calibration (Small BMD phantom set, Skyscan 1176, Bruker MicroCT, Kontich, Belgium). Density is defined as the volumetric density of calcium hydroxyapatite in terms of gram per cubic centimeter. The X-ray tube was operated at $50 \mathrm{kV}, 500 \mathrm{~mA}$ (0.5-mm Al filter, 1000-ms exposure time), and the scan was carried out by $180 \mathrm{f}$ rotation around the vertical axis with $0.55 \mathrm{f}$ rotation degree. At every position of the camera, two frames were taken and frame averaging was used. The 3D reconstruction was made by NRecon 1.6.6.0 software (Bruker MicroCT, Kontich, Belgium) with a value of $25 \%$ beam hardening correction. The $3 \mathrm{D}$ data standardization was performed by Dataviewer 1.4.4 (Bruker MicroCT, Kontich, Belgium). For the analysis CT Analyzer 1.13.2.1 (Bruker MicroCT, Kontich, Belgium) was used. After standardizing the position of the mandibles (Fig. 1a-c) we selected the volume ranging $900 \mu \mathrm{m}$ distally from the alveolar crest (100 slices) on the lower incisor (Fig. 1d). We compared the volume of the dentin, the enamel, and the pulp between wild-type and PACAP-deficient mice. We measured the total size of the tooth in this $900-\mu \mathrm{m}$ region (enamel volume + 
Fig. 1 Standardization of the position of the mandibles $(S P$ sagittal plane, $T P$ transverse plane, $F P$ frontal plane). The sagittal axis was aligned parallel to the central fissures of the molar teeth (b). The horizontal orientation was aligned to the occlusal plane $(\mathbf{a}, \mathbf{c})$. An area of $900 \mu \mathrm{m}$ was selected for evaluation distally from the alveolar crest (AC) (d). Volumes selected for measurement were as follows: enamel ( $E$, green line), dentin $(D$, red line), pulp $(P$, blue line) areas (e)
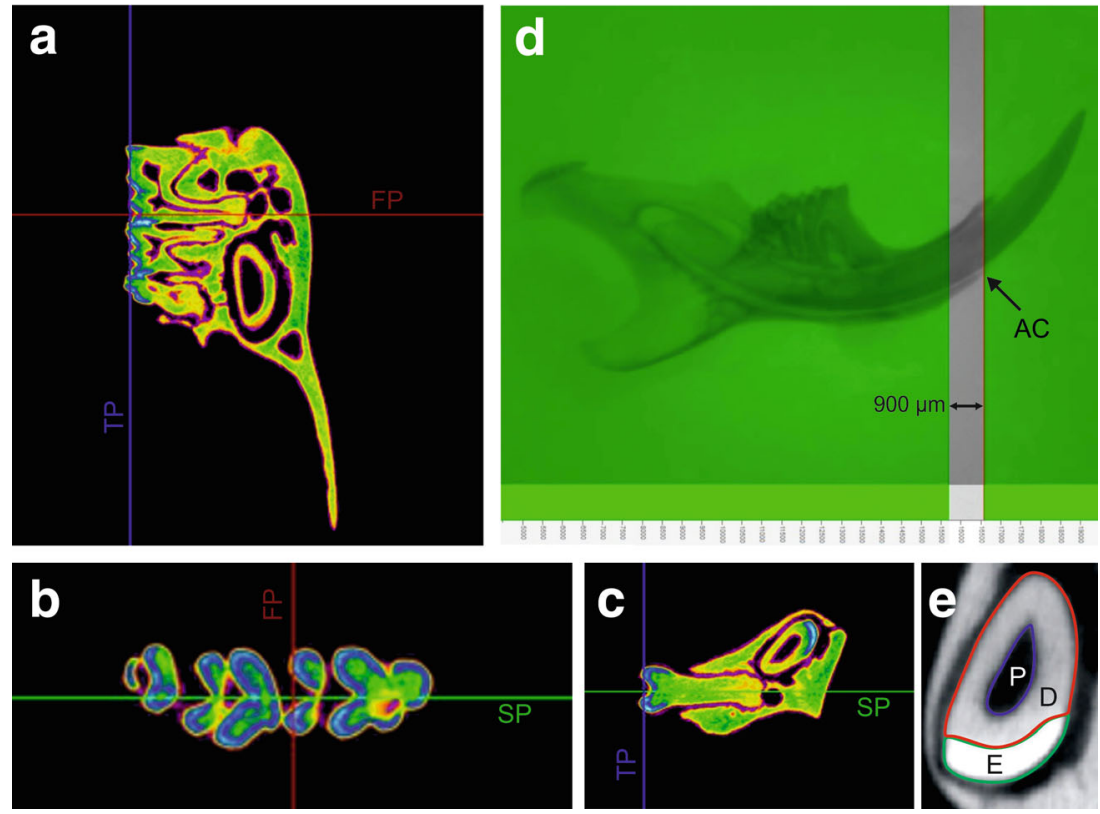

dentin volume + pulp chamber volume). To compare the size of the pulp chamber, pulp volume/dentin volume ratio, was used for correction of the data due to the size difference between the teeth (Fig. 1e). The density of the enamel, the dentin, and the mandibular bone was also evaluated by selecting the different volumes of interest in the analyzer software. The preparation, calibration, and density measurement of the samples were carried out in accordance with the Bruker method note (Bruker: bone mineral density (BMD) and tissue mineral trabecular density (TMD) calibration and measurement by micro-CT using Bruker-MicroCT CT-analyzer). For statistical analysis, Student's $t$ test was used in Microsoft Excel Software (Microsoft, USA).

\section{Raman Microscopy}

Raman microscopy is a well-recognized method for the analyses of the chemical structure of the teeth (Wang et al. 2007a; Matthaus et al. 2008; Xu et al. 2009; Sandor et al. 2014). After the micro-CT analyses, mandibles were used for Raman microscopy. The mandibles were embedded in epoxy resin in a standardized position. Frontal thin-ground-sections were made for spectral analyses from the area right before (incisally) the first molars. Structural comparison was carried out by using Thermo Scientific DXR Raman Microscope with equipment and settings previously described by us (Sandor et al. 2014). Briefly summarized, the Raman microscope was equipped with Olympus BX41 confocal microscope and CCD (charge-coupled device) detector, 532-nm Nd-YAG laser source. A 900-line/mm grating, a 50- $\mu \mathrm{m}$ confocal pinhole, and a 10-mW laser power was used during all measurements. A $\times 100$ Olympus objective was focused onto the specimens and the spectra were collected in $50-3546 \mathrm{~cm}^{-1}$ region.
Spectra were acquired from ten to ten discrete points from the middle of the enamel and dentin layers of each specimen (Fig. 2.) On the spectra of the enamel hydroxyapatite bands, on the spectra of the dentin, both hydroxyapatite and protein (amide III) bands could be observed. Raman bands of protein could not be detected on the spectra of the enamel, as the enamel in this area of the tooth is in maturation phase, the protein weight drops to $2 \%$ (Fukae and Shimizu, 1974; Smith and Nanci, 1989; Bartlett, 2013). After baseline corrections the areas under the phosphate, carbonate, and amide III $1240 / 1270 \mathrm{~cm}^{-1}$ peaks were measured by peak fitting procedure. On the Raman spectrum of the enamel characteristic bands of hydroxyapatite could be identified, but they were discarded due to the varied structural composition in width and apico-incisal dimension of the layer (Smith and Nanci 1989; Xu et al. 2009; Xu and Wang, 2012). During the examination of the dentin layer, the dentino-enamel junction was avoided because of its distinct composition (Walker and Fricke 2006; Xu et al. 2009). In the dentin layer the spectra were acquired from the middle of its width. For spectral analyses of the hydroxyapatite band in the dentin, we compared the ratio of area under the carbonate and phosphate peak $\left(\nu_{1} \mathrm{CO}_{3}{ }^{2-} / \nu_{1} \mathrm{PO}_{4}{ }^{3-}\right)$. The ratio used corresponds to the concentration of carbonate within the hydroxyapatite structure (Santos and Clayton, 1995). During the analyses of the protein spectra in the dentin amide III $\left(\delta \mathrm{C}-\mathrm{N}\right.$ at $1240 \pm 2 \mathrm{~cm}^{-1}$ and $\delta \mathrm{N}-\mathrm{H}$ at $1270 \pm 6 \mathrm{~cm}^{-1}$ ) deformation bands could be observed, which are widely used for describing the secondary structures of proteins (Dollish et al. 1974; Penel et al. 1997). We examined the ratio of the area under the amide III 1240/1270 peaks. Two-tailed t-test was carried out with IBM SPSS Statistics Version 17.0 after parameters were tested for normality. 


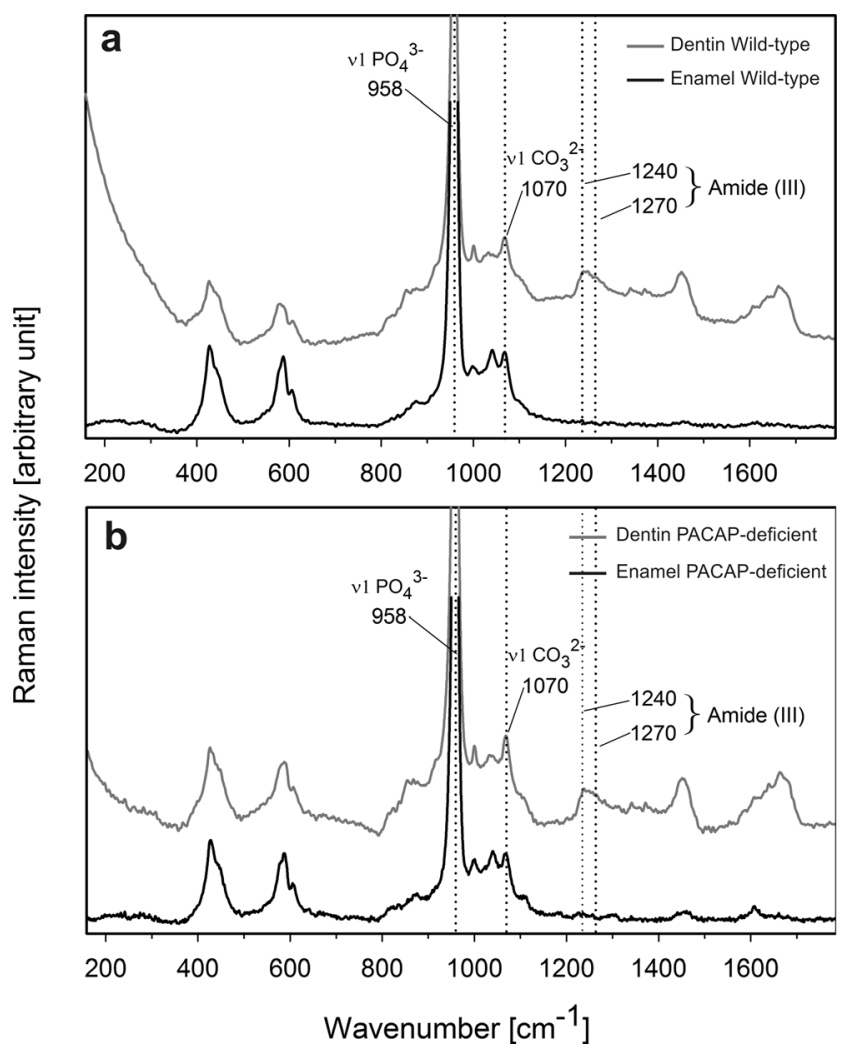

Fig. 2 Characteristic spectra of the dentin and enamel in wild-type (a) and PACAP-deficient mice (b). The $\nu_{1} \mathrm{PO}_{4}{ }^{3-}\left(958 \mathrm{~cm}^{-1}\right)$ and $\nu_{1} \mathrm{CO}_{3}{ }^{2-}$ (B-type at $1070 \mathrm{~cm}^{-1}$ ) peaks of hydroxyapatite could be observed in both the enamel and the dentin. Amide III $\left(\delta \mathrm{C}-\mathrm{N}\right.$ at $1240 \pm 2 \mathrm{~cm}^{-1}, \delta \mathrm{N}-\mathrm{H}$ at $1270 \pm 6 \mathrm{~cm}^{-1}$ ) deformation bands could be observed in the dentin, but not in the enamel, due to its low protein content

\section{Results}

\section{Micro-CT Morphometric Comparison}

We compared the size of teeth between wild-type and PACAP-deficient mice by adding the volumes of the enamel, dentin, and the pulp in the explored region (Fig. 1e). The size of the incisors (pulp + dentin + enamel volume) was significantly smaller in the PACAP-deficient mice $(p=0.044$; Fig. 3a). There were no significant differences between the volume of the dentin and the enamel separately. As the total size of the teeth is significantly smaller, the comparison of the pulp volume alone is misrepresentative; thereby, pulp chambers were compared by their ratio to the dentin. This ratio (pulp volume/dentin volume) of the PACAP-deficient mice was significantly smaller $(p=0.037$; Fig. $3 b-d)$ compared to wild-type animals.

\section{Density Measurements}

We compared the density of the alveolar bone, the enamel, and the dentin of wild-type and PACAP-deficient mice. We found
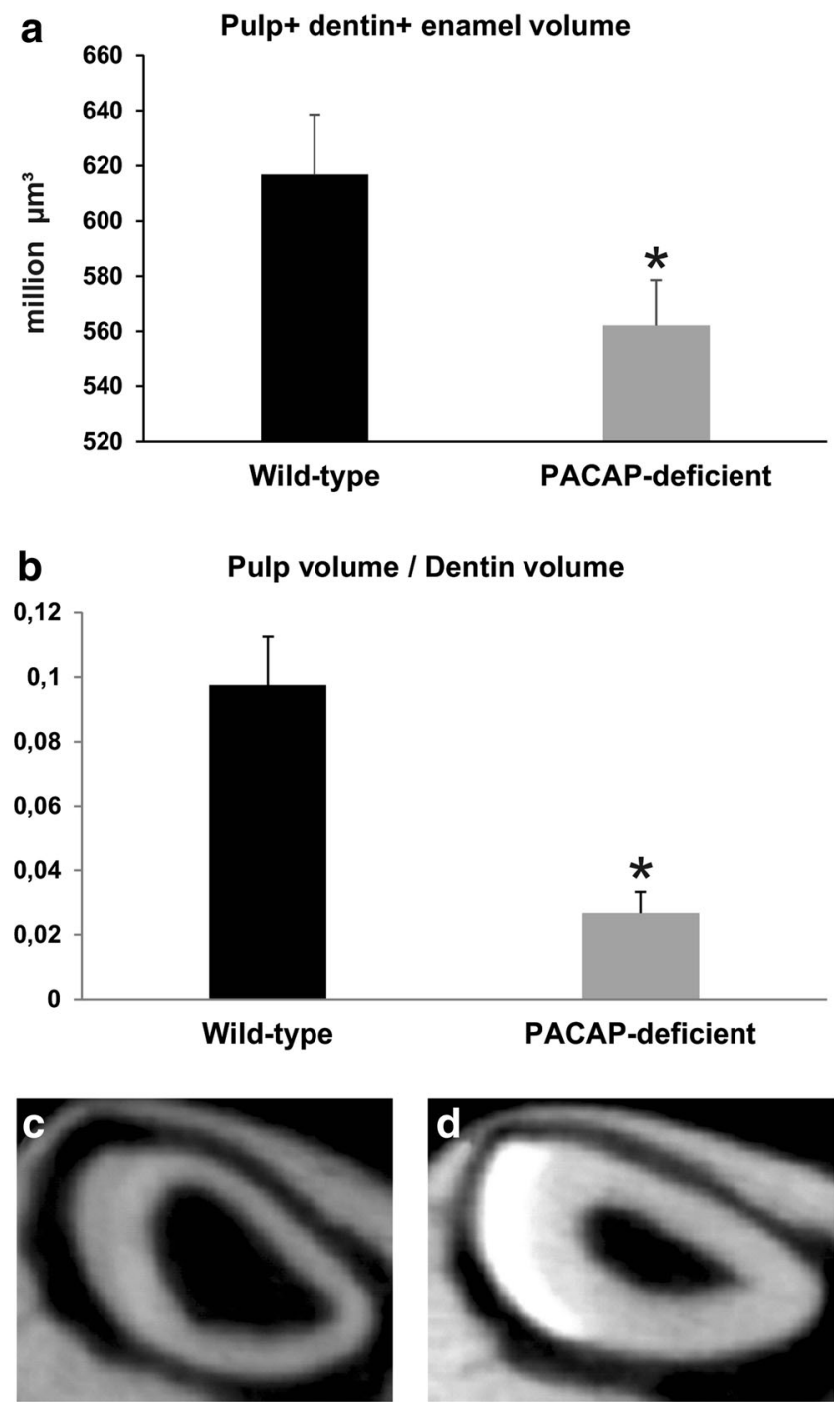

Fig. 3 Size of the incisors in the selected range (pulp + dentin + enamel volume) of wild-type and PACAP-deficient mice (a). Relative volume of the pulp (pulp volume/dentine volume) in wild-type and PACAPdeficient mice (b). Representative micro-CT scans of the incisors in wild-type (c) and PACAP-deficient mice (d)

significantly lower density in the dentin of the PACAPdeficient mice with the average of $0.396 \pm 0.033 \mathrm{~g} / \mathrm{cm}^{3}$ $( \pm \mathrm{SEM})$ compared to wild-type mice with the average value of $0.542 \pm 0.062 \mathrm{~g} / \mathrm{cm} 3$ ( \pm SEM; $p=0.044$; Fig. 4). No significant difference could be observed in the density of the enamel and the mandibular bone (data not shown).

\section{Raman Microscopy}

On the hydroxyapatite band of the dentin, we found significant $(p<0.05)$ difference between the ratio of the area under the carbonate and phosphate peaks $\left(v_{1} \mathrm{CO}_{3}{ }^{2-} / v_{1} \mathrm{PO}_{4}{ }^{3-}\right)$. This ratio is widely used to characterize the crystal structure of bioapatite. In wild-type mice the values are distributed between $0.1-0.27$ with the average of 0.16 . The ratio ranges 
Fig. 4 The density of calcium hydroxyapatite $\left(\mathrm{g} / \mathrm{cm}^{3}\right)$ in the dentin of wild-type and PACAPdeficient mice with micro-CT TMD measurement

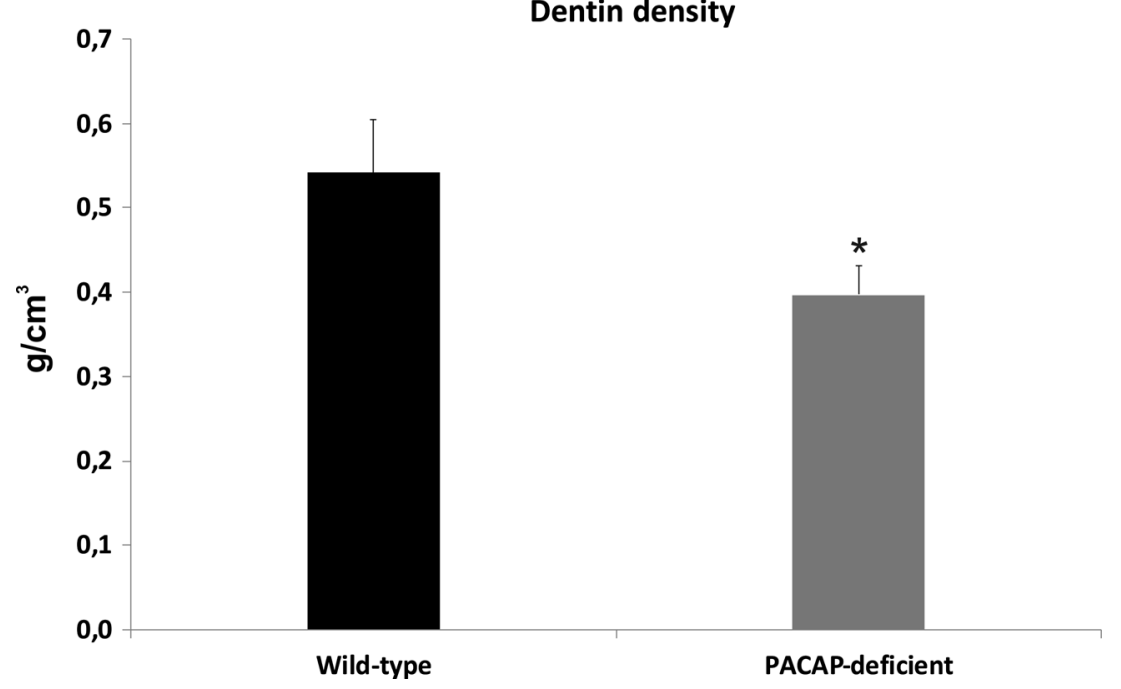

between $0.12-0.26$ in the PACAP-deficient mice, with the average value of 0.18 (Figs. 5 and 7). In the protein structure of the dentin, we found significant difference $(p<0.03)$ in the ratio of the area under the amide III $1240 / 1270 \mathrm{~cm}^{-1}$ peaks. The ratios are distributed in a wider range in wild-type mice. In wild-type mice the values are distributed between 0.14 1.57 with the average of 0.77 . The ratio ranges between 0.28-1.24 in the PACAP-deficient mice with the average value of 0.61 which is significantly lower compared to wild-type animals (Figs. 6 and 7). The results from the enamel layer were disregarded during structural examination due to the reasons previously described.

\section{Discussion}

We found significant differences between wild-type and PACAP-deficient mice with morphometric measurements carried out with micro-CT. The measurements revealed that the incisors were significantly smaller and the size of the pulp chambers related to the dentin volume was also significantly smaller in PACAP-deficient mice compared to wild-type animals. The smaller tooth is also in accordance with results showing that PACAP-deficient mice have retarded body growth, as shown by reduced weight gain (Kiss et al. 2010). The narrowing of the pulp chamber is physiologic with aging, but it may also occur as a defensive reaction to mechanical stimuli or bacterial noxa to the dental pulp. Sometimes, it is associated with dentin developmental disorders, as dentinogenesis imperfecta (Hart and Hart, 2007; Nanci, 2008; McCabe and Dummer, 2012; Hargreaves and Berman, 2016).

With TMD measurements, the volumetric density of calcium hydroxyapatite in the dentin of the PACAP-deficient mice was significantly lower. With Raman microscopy we also found significant difference in the hydroxyapatite structure of the dentin. The higher mean value of carbonate/phosphate ratio in PACAP-deficient mice indicates higher ionic substitution of $\mathrm{PO}_{4}{ }^{3-}$ by $\mathrm{CO}_{3}{ }^{2-}$ (B-type substitution) in the apatite structure. This results in a higher disordering in the dentinal structure with smaller crystallite size (de Mul et al. 1986; Penel et al. 1998; Thomas et al. 2007, 2011). The higher relative carbonate content of the dentin in the PACAPdeficient group correlates with our previous findings in 7 day-old mice (Sandor et al., 2014). The results of TMD measurement and the structural analyses may be in accordance. During mineral density measurements, X-ray attenuation is assumed to be related to the calcium-hydroxyapatite content
Fig. 5 Distribution of $v_{1} \mathrm{CO}_{3}{ }^{2-} / v_{1} \mathrm{PO}_{4}{ }^{3-}$ (1071/958) area ratios in wild-type and PACAP-deficient mice
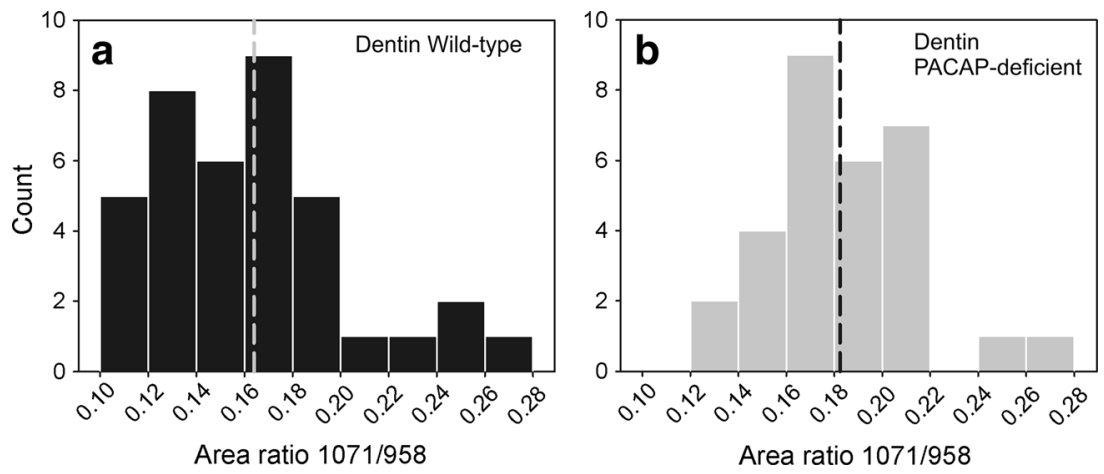
Fig. 6 Distribution of amide III $1240 / 1270$ area ratios in wildtype and PACAP-deficient mice
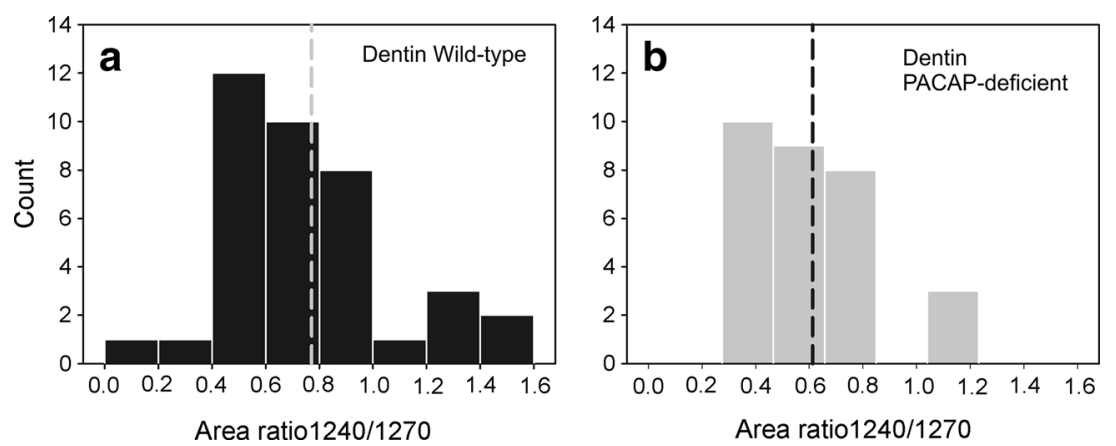

of hard tissues (bone, dentin, and enamel). Although we found no data on the relationship between carbonate/phosphate ratio and bone mineral density (BMD or TMD for tooth), in osteoporosis, higher carbonate/phosphate ratio was also associated with lower BMD (Faibish et al. 2006). The increase in carbonate content is related to an increase in the solubility and a disturbance in the local lattice order of biominerals, as smaller crystallite size gives a higher specific surface available for acid attacks (Featherstone and Lussi, 2006).

Regarding the organic components of the dentin, the wider range 1240/1270 peaks in the amide III band of wild-type mice refer to a higher structural diversity (more random coils) in the secondary structure of the proteins. Dentin proteins are composed of type-I collagen (predominantly) and other proteins and proteoglycans termed as non-collagenous proteins (NCPs). NCPs and especially SIBLINGs (small-integrinbinding ligand, N-linked glycoproteins), which are a category of NCPs, play an important role in the regulation of crystal growth and mineralization (Butler and Ritchie, 1995; Qin et al. 2004; Orsini et al. 2009). Although information is lacking about the exact mechanisms of dentin formation and mineralization, it has been shown that there is a slight conformational change in the secondary structure of dentin matrix protein-1 (DMP1-a member of the SIBLING family)

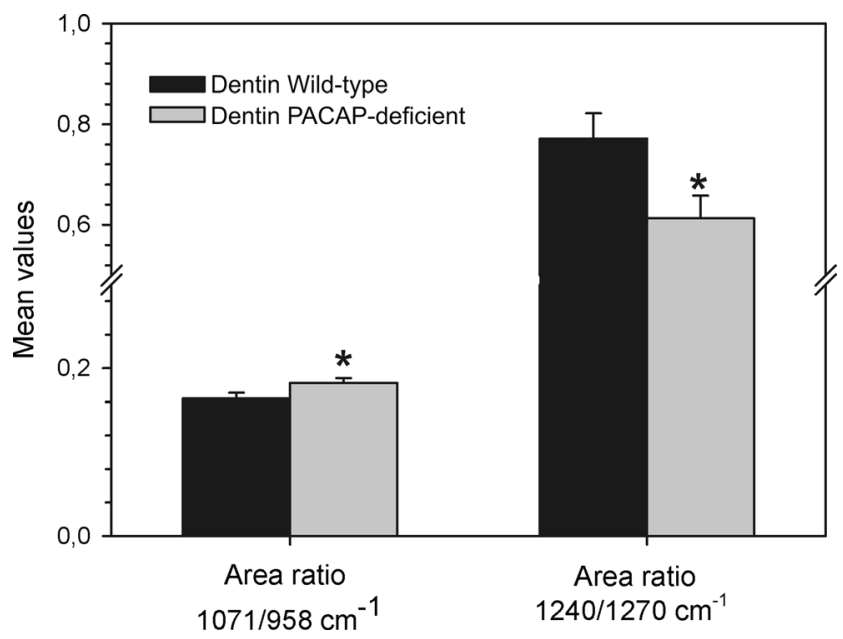

Fig. 7 Area ratios of $\nu_{1} \mathrm{CO}_{3}{ }^{2-}$ (B-type at $1071 \mathrm{~cm}^{-1}$ ) to $\nu_{1} \mathrm{PO}_{4}{ }^{3-}(958$ $\mathrm{cm}^{-1}$ ) and amide III $1240 \pm 2 \mathrm{~cm}^{-1}$ to $1270 \pm 6 \mathrm{~cm}^{-1}$ peaks of dentin in wild-type and PACAP-deficient mice (mean $\pm \mathrm{SEM}$ ) associated with binding to hydroxyapatite (Gericke et al., 2010). Random coil structure allows SIBLINGs to interact with minerals, collagen, and cell surfaces (Boskey and Robey, 2013).

The morphology, hard tissue formation, and size of the incisors are determined by a fine balance between the signaling pathways involved in tooth development (Wang et al. 2007b; Tummers and Thesleff, 2009; Jussila and Thesleff, 2012). Although there are differences between the regulation of development in the incisors and the molars of mice, the most important signaling molecules studied in their development are the bone morphogenetic proteins (BMP), the Hedgehog families (Hh), especially sonic hedgehog (Shh), fibroblast growth factors (FGF), and Wnt (Kieffer et al., 1999; Zhang et al. 2005; Bei, 2009). In spite of the great progress in identifying factors and molecules in tooth development, the exact mechanism of these signaling pathways remain unclear. Many other neurotrophins are also important in tooth development, such as nerve growth factor (NGF), brain-derived neurotrophic factor (BDNF), neurotrophin 3 (NT3), and neurotrophin 4 (NT4) (Mitsiadis and Luukko 1995; Luukko et al. 1996, 1997; Nosrat et al. 1998, 2002; Iwamoto et al. 2011). Previously, it was proven that PACAP alters the expression and effect of some of these factors in other tissues. Mesenchymal Wnt/ $\beta$-catenin signaling inhibits antiapoptotic effects of Fgfl0 on stem cells, in the mesenchyme surrounding the cervical loop of the incisors (Yang et al., 2015). It has been shown that altered expression of Fgf10 (Fgf10-deficient mice, delayed expression of mesenchymal Fgf10) results in decreased incisor size (Yokohama-Tamaki et al. 2006; Kyrylkova et al. 2012). The ligand-independent intrinsic/basal activity of PACAP-specific PAC1 receptor plays a key role in the activation and fine control of $\mathrm{Wnt} / \beta$-catenin signaling pathway through the dimerization of the PAC1 receptor. It has been proposed that the binding of PACAP to the receptor may interrupt the dimerization of the receptor, thus blocking the ligand-independent activity (Yu et al. 2014). So, we assume that in the ligandindependent activity and consequently the Wnt/ $\beta$-catenin signaling pathway may be enhanced in PACAP-deficient mice.

The binding of Shh to protein patched homolog 1 (PTCH1) receptor regulates the growth and morphogenesis of the teeth 
(Hardcastle et al. 1998; Dassule et al. 2000; Cobourne et al. 2001; Gritli-Linde et al. 2002). PACAP is considered to be a suppressor of the Shh signaling pathway in neuronal and nonneuronal tissues (Hirose et al. 2011; Niewiadomski et al. 2013, Juhasz et al. 2015b). Previously, with immunohistochemistry on SHH, PTCH1, and Gli1 (downstream target of PTCH), we detected significant differences between the molars of 7-dayold PACAP-deficient and wild-type mice. We found enhanced Shh signaling in the ameloblasts and the stratum intermedium in the developing molars of PACAP-deficient mice. PTCH1 expression was also increased in the ameloblasts and the Tomes' fibers in the PACAP-deficient group. Intracellular Glil accumulation was more visible in the deficient group compared to wild-type mice (Sandor et al. 2014). Out of all the signaling pathways involved in the regulation of tooth development, BMP's have a great significance. The fine tuning of BMP activity is essential in the morphoregulation of tooth development and the histogenesis and differentiation of ameloblasts and odontoblasts (Plikus et al., 2005). BMP signaling pathways are regulated by PACAP; moreover, the administration of PACAP to osteosarcoma cell line (UMR106) increased expression of BMPs and one of its major receptors BMPR1 (Pavelock et al. 2007; Juhasz et al. 2015b).

Based upon our present and previous results, it is obvious that PACAP plays an important role in tooth development with the regulation of morphogenesis, dentin, and enamel mineralization. Further studies are required to clarify the molecular background of the effects of PACAP on tooth development.

Acknowledgments The study was supported by: OTKA (K104984), TAMOP 4.2.4.A/2-11-1-2012-0001,National Excellence Program”, Arimura Foundation, Bolyai Scholarship, "Lendulet" Program of the Hungarian Academy of Sciences. The authors thank Tamas Kiss for his assistance in micro-CT examinations.

\section{References}

Arimura A, Somogyvari-Vigh A, Weill C, et al. (1994) PACAP functions as a neurotrophic factor. Ann N Y Acad Sci 739:228-243

Bartlett JD (2013) Dental enamel development: proteinases and their enamel matrix substrates. ISRN Dent 2013:684607 Review

Bei M (2009) Molecular genetics of tooth development. Curr Opin Genet Dev 19:504-510

Blechman J, Levkowitz G (2013) Alternative splicing of the pituitary adenylate cyclase-activating polypeptide receptor PAC1: mechanisms of fine tuning of brain activity. Front Endocrinol (Lausanne) 4:55

Boskey AL, Robey PG (2013) The regulatory role of matrix proteins in mineralization of bone in osteoporosis. Vol. 1. Marcus R, Feldman D, Dempster DW, Luckey M, Cauley JA; 4th ed. Elsevier Academic Press, Waltham, MA, pp. 235-255.

Butler WT, Ritchie H (1995) The nature and functional significance of dentin extracellular matrix proteins. Int J Dev Biol 39:169-179

Cobourne MT, Hardcastle Z, Sharpe PT (2001) Sonic hedgehog regulates epithelial proliferation and cell survival in the developing tooth germ. J Dent Res 80:1974-1979
Dassule HR, Lewis P, Bei M, Maas R, McMahon AP (2000) Sonic hedgehog regulates growth and morphogenesis of the tooth. Development 127:4775-4785

de Mul FF, Hottenhuis MH, Bouter P, Greve J, Arends J, ten Bosch JJ (1986) Micro-Raman line broadening in synthetic carbonated hydroxyapatite. J Dent Res 65:437-440

Dollish FR, Fateley WG, Bentley FF (1974) Characteristic Raman frequencies of organic compounds. Wiley, New York

Faibish D, Ott SM, Boskey AL (2006) Mineral changes in osteoporosis: a review. Clin Orthop Relat Res 443:28-38 Review

Featherstone JD, Lussi A (2006) Understanding the chemistry of dental erosion. Monogr Oral Sci 20:66-76

Fukae M, Shimizu M (1974) Studies on the proteins of developing bovine enamel. Arch Oral Biol 19:381-386

Gericke A, Qin C, Sun Y, et al. (2010) Different forms of DMP1 play distinct roles in mineralization. J Dent Res 89:355-359

Goldberg M, Kellermann O, Dimitrova-Nakov S, Harichane Y, Baudry A (2014) Comparative studies between mice molars and incisors are required to draw an overview of enamel structural complexity. Front Physiol 5:359

Gritli-Linde A, Bei M, Maas R, Zhang XM, Linde A, McMahon AP (2002) Shh signaling within the dental epithelium is necessary for cell proliferation, growth and polarization. Development 129: $5323-5337$

Hardcastle Z, Mo R, Hui CC, Sharpe PT (1998) The Shh signaling pathway in tooth development: defects in Gli2 and Gli3 mutants. Development 125:2803-2811

Hargreaves KM, Berman LH (2016) Vital pulp therapy in Cohen's pathways of the pulp expert consult, 11th edn. Elsevier, St. Louis, pp. 849-476

Hart PS, Hart TC (2007) Disorders of human dentin. Cells Tissues Organs 186:70-77

Hashimoto H, Shintani N, Tanaka K, et al. (2001) Altered psychomotor behaviors in mice lacking pituitary adenylate cyclase activating polypeptide (PACAP). Proc Natl Acad Sci U S A 98:13355-13360

Hashimoto H, Hashimoto R, Shintani N, et al. (2009) Depression-like behavior in the forced swimming test in PACAP-deficient mice: amelioration by the atypical antipsychotic risperidone. $\mathrm{J}$ Neurochem 110:595-602

Hirose M, Niewiadomski P, Tse G, et al. (2011) Pituitary adenylyl cyclase-activating peptide counteracts hedgehog-dependent motor neuron production in mouse embryonic stem cell cultures. J Neurosci Res 89:1363-1374

Ichikawa H, Sugimoto T (2003) Pituitary adenylate cyclase-activating polypeptide-immunoreactive nerve fibers in rat and human tooth pulps. Brain Res 980:288-292

Iwamoto T, Yamada A, Arakaki M, et al. (2011) Expressions and functions of neurotrophic factors in tooth development. J Oral Biosci 53:13-21

Juhasz T, Matta C, Katona E, et al. (2014) Pituitary adenylate cyclaseactivating polypeptide (PACAP) signalling enhances osteogenesis in UMR-106 cell line. J Mol Neurosci 54:555-573

Juhasz T, Helgadottir SL, Tamas A, Reglodi D, Zakany R (2015a) PACAP and VIP signaling in chondrogenesis and osteogenesis. Peptides 66:51-57

Juhasz T, Szentleleky E, Somogyi C, et al. (2015b) Pituitary adenylate cyclase activating polypeptide (PACAP) pathway is induced by mechanical load and reduces the activity of hedgehog signaling in chondrogenic micromass cell cultures. Int J Mol Sci 16: 17344-17367

Jussila M, Thesleff I (2012) Signaling networks regulating tooth organogenesis and regeneration, and the specification of dental mesenchymal and epithelial cell lineages. Cold Spring Harb Perspect Biol 4: a008425 
Kiss P, Farkas J, Horvath G, et al. (2010) Neurobehavioral development in PACAP (pituitary adenylate cyclase activating polypeptide) knockout mice. FENS Abstr., vol. 5, 042.7

Kieffer S, Peterkova R, Vonesch JL, Ruch JV, Peterka M, Lesot H (1999) Morphogenesis of the lower incisor in the mouse from the bud to early bell stage. Int J Dev Biol 43:531-539

Kyrylkova K, Kyryachenko S, Biehs B, Klein O, Kioussi C, Leid M (2012) BCL11B regulates epithelial proliferation and asymmetric development of the mouse mandibular incisor. PLoS One 7:e37670

Lelievre V, Ghiani CA, Seksenyan A, Gressens P, deVellis J, Waschek JA (2006) Growth factor-dependent actions of PACAP on oligodendrocyte progenitor proliferation. Regul Pept 137:58-66

Luukko K, Moshnyakov M, Sainio K, Saarma M, Sariola H, Thesleff I (1996) Expression of neurotrophin receptors during rat tooth development is developmentally regulated, independent of innervation, and suggests functions in the regulation of morphogenesis and innervation. Dev Dyn 206:87-99

Luukko K, Arumae U, Karavanov A, et al. (1997) Neurotrophin mRNA expression in the developing tooth suggests multiple roles in innervation and organogenesis. Dev Dyn 210:117-129

Matthaus C, Bird B, Miljkovic M, Chernenko T, Romeo M, Diem M (2008) Infrared and Raman microscopy in cell biology (chapter 10). Methods Cell Biol 89:275-308

McCabe PS, Dummer PM (2012) Pulp canal obliteration: an endodontic diagnosis and treatment challenge. Int Endod J 45:177-197 Review

Mitsiadis TA, Luukko K (1995) Neurotrophins in odontogenesis. Int J Dev Biol 39:195-202

Nanci A (2008) Dentin-pulp complex in ten Cate's oral histology: development, structure, and function, 7th edn. Mosby, St. Louis, pp. $191-238$

Nicot A, Lelievre V, Tam J, Waschek JA, DiCicco-Bloom E (2002) Pituitary adenylate cyclase activating polypeptide and sonic hedgehog interact to control cerebellar granule precursor cell proliferation. J Neurosci 22:9244-9254

Niewiadomski P, Zhujiang A, Youssef M, Waschek JA (2013) Interaction of PACAP with sonic hedgehog reveals complex regulation of the hedgehog pathway by PKA. Cell Signal 25:2222-2230

Nonaka S, Kitaura H, Kimura K, Ishida M, Takano-Yamamoto T (2013) Expression of pituitary adenylate cyclase-activating peptide (PACAP) and PAC1 in the periodontal ligament after tooth luxation. Cell Mol Neurobiol 33:885-892

Nosrat CA, Fried K, Ebendal T, Olson L (1998) NGF, BDNF, NT3, NT4 and GDNF in tooth development. Eur J Oral Sci 106:94-99

Nosrat I, Seiger A, Olson L, Nosrat CA (2002) Expression patterns of neurotrophic factor mRNAs in developing human teeth. Cell Tissue Res 310:177-187

Orsini G, Ruggeri A, Mazzoni A, et al. (2009) A review of the nature, role, and function of dentin non-collagenous proteins. Part 1: proteoglycans and glycoproteins. Endod Top 21:1-18

Otto C, Schutz G, Niehrs C, Glinka A (2000) Dissecting GHRH- and pituitary adenylate cyclase activating polypeptide-mediated signalling in Xenopus. Mech Dev 94:111-116

Pavelock KA, Girard BM, Schutz KC, Braas KM, May V (2007) Bone morphogeneticprotein down-regulation of neuronal pituitary adenylate cyclase-activating polypeptide and reciprocal effects on vasoactive intestinal peptide expression. J Neurochem 100:603-616

Penel G, Leroy G, Rey C, Sombret B, Huvenne JP, Bres E (1997) Infrared and Raman microspectrometry study of fluor-fluor-hydroxy and hydroxyl-apatite powders. J Mater Sci Mater Med 8:271-276

Penel G, Leroy G, Rey C, Bres E (1998) MicroRaman spectral study of the $\mathrm{PO} 4$ and $\mathrm{CO} 3$ vibrational modes in synthetic and biological apatites. Calcif Tissue Int 63:475-481

Plikus MV, Zeichner-David M, Mayer JA, et al. (2005) Morphoregulation of teeth: modulating the number, size, shape and differentiation by tuning Bmp activity. Evol Dev 7:440-457
Qin C, Baba O, Butler WT (2004) Post-translational modifications of sibling proteins and their roles in osteogenesis and dentinogenesis. Crit Rev Oral Biol Med 15:126-136

Reglodi D, Kiss P, Lubics A, Tamas A (2011) Review on the protective effects of PACAP in models of neurodegenerative diseases in vitro and in vivo. Curr Pharm Des 17:962-972

Reglodi D, Kiss P, Szabadfi K, et al. (2012) PACAP is an endogenous protective factor-insights from PACAP-deficient mice. J Mol Neurosci 48:482-492

Shen S, Gehlert DR, Collier DA (2013) PACAP and PAC1 receptor in brain development and behavior. Neuropeptides 47:421-430

Sandor B, Fintor K, Felszeghy S, et al. (2014) Structural and morphometric comparison of the molar teeth in pre-eruptive developmental stage of PACAP-deficient and wild-type mice. J Mol Neurosci 54: 331-341

Santos RV, Clayton RN (1995) The carbonate content in high temperature apatite; an analytical method applied to apatite from the Jacupiranga alkaline complex. Am Min 80:336-344

Smith CE, Nanci A (1989) A method for sampling the stages of amelogenesis on mandibular rat incisors using the molars as a reference for dissection. Anat Rec 225:257-266

Tajiri M, Hayata-Takano A, Seiriki K, et al. (2012) Serotonin 5-HT (7) receptor blockade reverses behavioral abnormalities in PACAPdeficient mice and receptor activation promotes neurite extension in primary embryonic hippocampal neurons: therapeutic implications for psychiatric disorders. J Mol Neurosci 48:473-481

Thesleff I, Nieminen P (1996) Tooth morphogenesis and cell differentiation. Curr Opin Cell Biol 8:844-850

Thesleff I (2006) The genetic basis of tooth development and dental defects. Am J Med Genet A 140:2530-2535

Thomas DB, Fordyce RE, Frew RD, Gordon KC (2007) A rapid, nondestructive method of detecting diagenetic alteration in fossil bone using Raman spectroscopy. J Raman Spectrosc 38:1533-1537

Thomas DB, McGoverin CM, Fordyce RE, Frew RD, Gordon KC (2011) Raman spectroscopy of fossil bioapatite - a proxy for diagenetic alteration of the oxygen isotope composition. Palaeogeogr Palaeocl 310:62-70

Tummers M, Thesleff I (2009) The importance of signal pathway modulation in all aspects of tooth development. J Exp Zool B Mol Dev Evol 312B:309-319

Vaudry D, Falluel-Morel A, Bourgault S, et al. (2009) Pituitary adenylate cyclase-activating polypeptide and its receptors: 20 years after the discovery. Pharmacol Rev 61:283-357

Walker MP, Fricke BA (2006) Dentin-enamel junction of human teeth in: Akay M (ed) Wiley encyclopedia of biomedical engineering. Wiley, Hoboken, pp. 1061-1064

Wang Y, Spencer P, Walker MP (2007a) Chemical profile of adhesive/ caries-affected dentin interfaces using Raman microspectroscopy. J Biomed Mater Res A 81:279-286

Wang XP, Suomalainen M, Felszeghy S, et al. (2007b) An integrated gene regulatory network controls stem cell proliferation in teeth. PLoS Biol 5:e159

Watanabe J, Nakamachi T, Matsuno R, et al. (2007) Localization, characterization and function of pituitary adenylate cyclase-activating polypeptide during brain development. Peptides 28:1713-1719

Xu C, Yao X, Walker MP, Wang Y (2009) Chemical/molecular structure of the dentin-enamel junction is dependent on the intratooth location. Calcif Tissue Int 84:221-228

Xu C, Wang Y (2012) Chemical composition and structure of peritubular and intertubular human dentine revisited. Arch Oral Biol 57: 383-391

Yang Z, Balic A, Michon F, Juuri E, Thesleff I (2015) Mesenchymal Wnt/ $\beta$-catenin signaling controls epithelial stem cell homeostasis in teeth by inhibiting the antiapoptotic effect of Fgf10. Stem Cells 33:1670-1681 
Yokohama-Tamaki T, Ohshima H, Fujiwara N, et al. (2006) Cessation of Fgf10 signaling, resulting in a defective dental epithelial stem cell compartment, leads to the transition from crown to root formation. Development 133:1359-1366

Yu R, Cui Z, Li M, Yang Y, Zhong J (2014) Dimer-dependent intrinsic/ basal activity of the class B G protein-coupled receptor PAC1 promotes cellular anti-apoptotic activity through $\mathrm{Wnt} / \beta$-catenin pathways that are associated with dimer endocytosis. PLoS One 9: e113913

Zhang YD, Chen Z, Song YQ, Liu C, Chen YP (2005) Making tooth: growth factors, transcription factors and stem cells. Cell Res 15: $301-316$ 